\title{
Movimiento indígena y sistema político en Ecuador (2012) de Edgar Tello
}

\author{
The indigenous movement and political system in
} Ecuador (2012) by Edgar Tello

\section{J. Sánchez Parga}

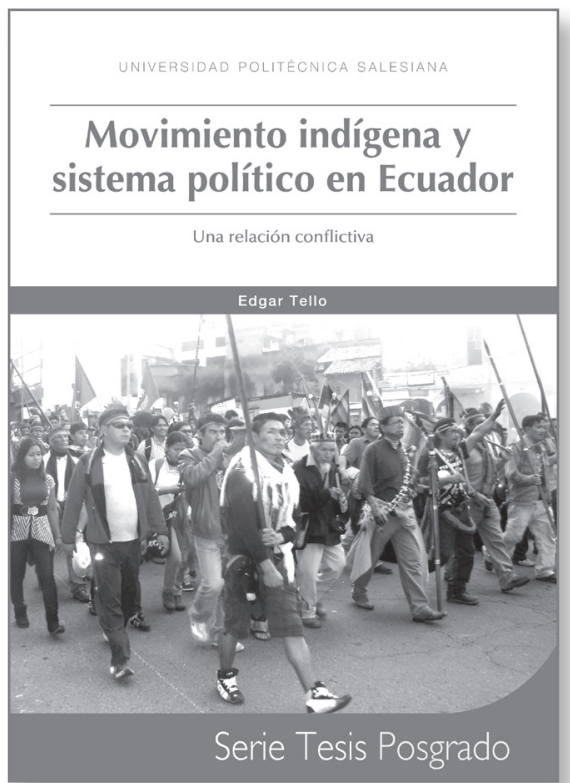

El estudio de Edgar Tello, Movimiento indigena y sistema político en Ecuador (UPS/Abya-Yala, Quito, 2012), al igual que otras dos obras anteriores, la de Augusto Barrera, Acción colectiva y crisis política. El movimiento indígena ecuatoriano en la década de los noventa (OSAL/CLASO, Ciudad, Abya-Yala, Quito, 2001), y de J. Sánchez Parga El movimiento indígena ecuatoriano. La larga marcha de la comunidad al partido (Caap, Quito, 2007; 2a Ed. AbyaYala, Quito 2010), todas coinciden en analizar la formación, el desarrollo o las actuaciones del movimiento indígena no sólo a partir de los procesos históricos, socio-políticos, del Ecuador, sino también desde la influencia que dicho movimiento ha ejercido en los cambios de la moderna sociedad ecuatoriana.

En este sentido, estos trabajos se diferencian de aquellos realizados desde el exterior, casi exclusivamente centrados en el análisis y evolución del movimiento indígena, sin tener en cuenta sus inserciones y relaciones con los procesos 
de la sociedad nacional y de su sistema político. Sólo la obra de Xavier Albó, Movimientos indígenas y poder indígena en Bolivia, Ecuador y Perú (Cipca, La Paz, 2008), aunque de manera general pone de relieve cómo el movimiento indígena es parte de los cambios operados en las poblaciones indígenas y también en los procesos político culturales de dichos países.

Para el estudio de Barrera el movimiento indígena no es más que un componente (y sólo un capítulo) dentro del análisis más amplio de la "acción colectiva", es decir, de los movimientos sociales, y en el marco de la crisis del sistema político ecuatoriano, que se precipita y agrava en la década de los 90, período analizado en el libro. En un artículo posterior ("El movimiento indígena ecuatoriano entre los actores sociales y el sistema político", Nueva Sociedad, n. 182, nov. - dic 2002) Barrera focaliza su reflexión sobre el movimiento indígena en referencia

Si la obra de Edgar Tello identifica la emergencia del movimiento indígena en los años 90, "a raíz de su primer levantamiento" (p.6), con una breve referencia a las décadas precedentes de su gestación, es porque el estudio tiene por objeto principal analizar, de manera específica, la relación e inserción del movimiento indígena en el sistema político nacional. En este sentido el autor va a privilegiar lo que llama "la dimensión" o "carácter" político del movimiento indígena (p.45).

Por esta razón también el estudio privilegia aquellas actuaciones más políticas del movimiento indígena durante las dos últimas décadas, como fueron las movilizaciones contra la Ley Agraria de 1994 y contra el precio del gas o las que participaron en los derrocamientos de Bucaram (1996) y Mahuad (2000).

Uno de los problemas teóricos e interesantes que plantea la obra de Tello es la supuesta politicidad o politización de los movimientos sociales. Y la cuestión resulta además muy pertinente, pues tiene que ver con el objeto de su estudio: movimiento indígena y sistema político.

Es falso, como sostiene la cita de Neveu (2000: 22) que para Touraine "los movimientos sociales son por definición un componente singular e importante de la participación política" (p.45). Aunque parezca perogrullada, un movimiento social es por definición social y no político. Para Touraine los movimientos son sociales, se identifican con el actor social, se rigen por la lógica del 
conflicto social, reivindicativo, no por la lógica del enemigo, del enfrentamiento y la oposición, que es precisamente lo que define al actor político.

Es obvio que la constitución de un nuevo actor social (movimiento) en el escenario de una sociedad comporta un conflicto con todos los demás actores que con sus propias reivindicaciones pugnan por una mayor participación social; pero este tipo de conflicto entre actores es social, pero no político, ya que no los convierte en enemigos entre sí.

Touraine reconoce que en América Latina los movimientos sociales son más políticos que sociales. Sin embargo no se puede confundir un movimiento social, que es parte de la sociedad civil y un movimiento, fuerza o partido político, que es parte del sistema político. Mientras que un movimiento social como el indígena es plural y diverso, y de hecho una es la historia del movimiento indígena de Imbabura, de Chimborazo, de Tungurahua o de Cotopaxi, ilustrado este último por el libro de Lourdes Tibán (Movimiento indígena y campesino de Cotopaxi, MICC. Historia y Proceso organizativo, IEE, Quito, 2003), la representación política de un partido presupone y requiere la unidad como postulado.

Pachakutik es un fenómeno muy paradójico, ya que en parte responde a la necesidad del movimiento social (indígena) de dotarse de una forma o aparato político, pero por otra parte aparece como un efecto de la politización del mismo movimiento indígena, que sin dejar de ser social y sujeto de una conducción social como todo movimiento, se vuelve cada vez más político y por consiguiente sujeto de una representación política.

Tello hace eco de este fenómeno y de su interpretación: "Pachakutik se constituye en una forma especial de tratar y abordar la necesidad de defender la autonomía del movimiento indígena en relación al sistema de partidos políticos, buscando romper con la lógica de subordinación o cooptación" (p.91). Sin embargo, como también constata el autor, ya en su primera participación electoral, en 1996, Pachakutik forma alianza con dos partidos, la ID y el PSE; después seguirá estableciendo alianzas electorales con Nuevo País, con el que será partido gobernante, Sociedad Patriótica en 2002, con el PSE y FADI en 2007. La única elección en que Pachakutik concurre con su propio candidato obtiene el $2.1 \%$ de los votos, lo que supone cuatro veces menos que el porcentaje de la población indígena del país. 